\title{
Childhood Schizophrenia
}

National Cancer Institute

\section{Source}

National Cancer Institute. Childhood Schizophrenia. NCI Thesaurus. Code C35004.

Schizophrenia occurring in childhood. 